\title{
Sectorial Technetium-99m-Dimercaptosuccinic Acid Scintigraphy for Monitoring the Effect of Extracorporeal Piezoelectric Lithotripsy for Calyceal Calculi on Regional Renal Function
}

\author{
A. Al-Tawheed ${ }^{a}$ K.A. Al-Awadi a E.O. Kehinde ${ }^{a} \quad$ I. Loutfi ${ }^{b}$ \\ H. Abdul-Haleem ${ }^{a}$ S. Al-Mohannadi ${ }^{b}$ \\ Departments of a Surgery (Division of Urology) and ' Nuclear Medicine, Mubarak Al-Kabeer Hospital, \\ Faculty of Medicine, Kuwait University, Kuwait
}

\section{Key Words}

Renal calyceal calculi - Extracorporeal piezoelectric lithotripsy - Technetium-99m-DMSA sectorial scintigraphy

\begin{abstract}
Objective: To apply a semiquantitative method for analysis of technetium-99m-dimercaptosuccinic acid (99mTcDMSA) renal scintigraphy for monitoring the effect of extracorporeal piezoelectric lithotripsy (EPL) in patients with calyceal stones on regional kidney function and to check whether EPL had caused any deleterious effect on the target calyceal renal parenchymal function. Patients and Methods: Forty patients (mean age 35 years) suffering from calyceal stones documented by abdominal plain radiography, intravenous urogram or abdominal ultrasound were studied. All patients were treated by EPL. ${ }^{99 m T c-D M S A ~ s c a n ~ w a s ~ p e r f o r m e d ~ b e f o r e ~ a n d ~} 4$ weeks after EPL. Sector analysis involved calculation of the relative function of the target calyx to the function of the ipsilateral kidney and the relative function of the treated kidney to global renal function. Results: The stone sizes were $6-11 \mathrm{~mm}$ in diameter and 11 were located in the upper, 13 in the middle and 16 in the lower
\end{abstract}

\section{KARGER}

Fax +41613061234

E-Mail karger@karger.ch

www. karger.com
(C) 2003 S. Karger AG, Basel

1011-7571/03/0123-0145\$19.50/0

Accessible online at:

www. karger.com/mpp calyx. After EPL, the overall stone clearance rate was $85 \%(100 \%$ for calculi in the upper and middle calyces, $62 \%$ for lower calyces). The sector analysis did not show statistically significant change of the relative regional (calyceal) or whole kidney function between the pre- and post-EPL 99mTc-DMSA scans. Using sector analysis, EPL appeared to be a safe modality and its usage was not associated with any untoward effect on calyceal or whole kidney function. Conclusion: Sector analysis of $99 \mathrm{mTc}-$ DMSA renal scan is a simple semiquantitative method for monitoring regional changes of kidney function after EPL for treatment of calyceal stone.

Copyright $@ 2003$ S. Karger AG, Basel

\section{Introduction}

Extracorporeal shock wave lithotripsy (ESWL) is currently a well-established procedure for the management of urinary stone disease which has greatly reduced the need for open stone surgery and percutaneous nephrolithotomy [1-5]. Variants of the shock wave generators commonly in use are the electrohydraulic, piezoelectric (EPL) and electromagnetic. Few serious side-effects have been reported due to shock wave trauma to the renal parenchyma, 
which, fortunately, are transient in nature and usually recover without sequelae $[6,7]$. However, in rare cases, permanent decrease in renal function after EPL can occur $[8,9]$. Also, significant alterations of renal growth after ESWL have been reported in children [10-12]. Similarly, experimental studies in immature rats exposed to shock wave therapy demonstrated long-term effects on renal function and permanent histological damage [13].

In clinical practice, technetium-99m-dimercaptosuccinic acid ( $99 \mathrm{~m}$ Tc-DMSA) scintigraphy, a non-invasive procedure, has been used to evaluate the impact of various pathological processes on the renal cortex including cortical functional integrity and quantitation of differential renal function [14]. ${ }^{99 \mathrm{~m} T c-D M S A}$ scintigraphy has been the most commonly used technique to study renal scarring after urinary tract infection [15]. In renal stones, there have been attempts at using ${ }^{99 \mathrm{~m} T c-D M S A}$ scintigraphy to assess renal functional status, but more importantly to evaluate the impact of interventions, especially ESWL (or EPL) on renal function [16-20]. In most cases, the studies have been based on visual interpretation of the scan in addition to the standard quantitation of split renal function. However, considering that the process of targeting a stone using ESWL or EPL involves delivery of tightly packed energy to it, the area of the kidney where the stone is located would suffer the worst effect from the procedure. Therefore, the measurement of the whole kidney function as given by the split renal function technique may have a dilution effect of the regional abnormality sustained at the site of the stone. In this study, we addressed the issue of alteration of regional renal function by EPL in patients with calyceal stones using sector analysis of 99m Tc-DMSA scintigraphy before and after EPL. We determined whether or not there was any deleterious effect of EPL on the target calyx and checked if a similar impact was evident on the whole kidney function measurement.

\section{Subjects and Methods}

Forty-three consecutive patients (30 males and 13 females) suffering from calyceal stones were included in the study. The average age of the patients was 35 years (range 25-41 years). The patients were selected from a larger group of patients with urinary calcular disease treated at the Stone Centre in Mubarak Al-Kabeer Hospital, Faculty of Medicine, Kuwait University, Kuwait. The diagnosis of calyceal stones was made by plain radiograph of the abdomen, intravenous urogram or abdominal ultrasound. Three patients who had a complicated course immediately after treatment requiring insertion of a ' $\mathrm{J}$ ' stent or other auxillary procedure were excluded from the study.
The patients had a full clinical and biochemical evaluation before and after EPL. Lithotripsy was performed using a Richard Wolf Piezolith 2300 (Knittlingen, Germany). This device employed an ultrasound system for stone localization and piezoelectric energy for its disintegration. The power of the shock waves was gradually increased over the first $10 \mathrm{~min}$ to $100 \%$ of the machine capacity (output setting up to 4), which gave a peak pressure of approximately 700 bar $(70 \mathrm{mPa})$ of focal zone $3 \times 10 \mathrm{~mm}^{2}$. The shock wave application was triggered as continuous pulses, up to 2 pulses per second. Four to five EPL sessions were required for every patient. The mean number of shock waves was 3,000 per session.

Renal scintigraphy was performed $2 \mathrm{~h}$ after intravenous administration of $185 \mathrm{MBq}(5 \mathrm{mCi})$ of ${ }^{99 \mathrm{~m}} \mathrm{Tc}-\mathrm{DMSA}$. Imaging was done in a supine position using a dual-head scintillation camera (Millennium, GE, USA) fitted with a low energy high resolution parallel hole collimator and interfaced to a computer. A $256 \times 256$ pixel matrix and a zoom of 2 was used. Static images of the abdomen in anterior, posterior and right and left posterior oblique were obtained for a preset time of $4 \mathrm{~min}$. Quantitative analysis was done on the anterior and the posterior images to calculate the sector (calyceal) function by the geometric mean method. This involved drawing regions of interest around the target calyx identified from the structural imaging prior to the scan or on the static ${ }^{99 \mathrm{~m} T c-D M S A}$ images. Another region is drawn on the whole kidney in addition to a background region. The product of the net count for the sector taken from the anterior and posterior views was obtained and the square root taken. The sector function was calculated by taking the ratio of sector geometric mean count to the whole kidney geometric mean count. The split renal function was also calculated using the standard geometric mean method in a similar way to that described for the sector analysis described above. ${ }^{99 \mathrm{~m}} \mathrm{Tc}$-DMSA scans were done before and 4 weeks after the EPL sessions. In both studies, the same method of analysis using the same regions of interest was applied.

\section{Statistical Analysis}

The Student's paired t test was used to calculate any statistical significance difference between pre- and post-EPL whole and sectorial renal function as measured by $99 \mathrm{~m}$ Tc-DMSA scan.

\section{Results}

The stone sizes as determined by abdominal plain radiography, intravenous urography or abdominal ultrasound were $6-11 \mathrm{~mm}$ in diameter. The locations of the stones are given in table 1 . Of the 43 patients, 40 completed the EPL sessions with successful fragmentation and clearance of the calyceal stone fragments from the upper and middle calyces. In the patients with lower calyceal calculi, residual stones were seen in 6 out of 16 cases $(37.5 \%)$. The overall stone clearance was $34 / 40(85 \%)$.

Typical ${ }^{99 \mathrm{~m} T c-D M S A}$ renal scans obtained from patients are shown in figure 1a, region of interest for sectorial analysis in figure $1 \mathrm{~b}$ and that of split renal function in figure 1c. The results of the sector and whole kidney analysis of the ${ }^{99 \mathrm{~m}} \mathrm{Tc}-\mathrm{DMSA}$ scan are shown in table 2 . There 
Table 1. Distribution of stones and stone clearance rates among the group studied

\begin{tabular}{|c|c|c|c|c|c|c|c|}
\hline \multirow{2}{*}{$\begin{array}{l}\text { Location } \\
\text { of calculus }\end{array}$} & \multicolumn{2}{|c|}{ Right kidney } & \multicolumn{2}{|c|}{ Left kidney } & \multirow[t]{2}{*}{ Total } & \multicolumn{2}{|c|}{ Stone clearance rate ${ }^{1}$} \\
\hline & male & female & male & female & & $\mathrm{n}$ & $\%$ \\
\hline Upper calyx & 6 & 1 & 2 & 2 & 11 & 11 & 100 \\
\hline Middle calyx & 4 & 3 & 4 & 2 & 13 & 13 & 100 \\
\hline Lower calyx & 6 & 3 & 6 & 1 & 16 & 10 & 62.5 \\
\hline
\end{tabular}

1 The overall stone clearance rate was $34 / 40(85 \%)$.

Table 2. The effect of treating calyceal stones using EPL on calyceal and whole kidney function as assessed by $99 \mathrm{~m}$ Tc-DMSA scan

\begin{tabular}{|c|c|c|c|c|c|c|}
\hline & \multicolumn{2}{|c|}{$\begin{array}{l}\text { Upper calyceal stones } \\
(\mathrm{n}=11)\end{array}$} & \multicolumn{2}{|c|}{$\begin{array}{l}\text { Middle calyceal stones } \\
(\mathrm{n}=13)\end{array}$} & \multicolumn{2}{|c|}{$\begin{array}{l}\text { Lower calyceal stones } \\
(\mathrm{n}=16)\end{array}$} \\
\hline & pre EPL & post EPL & pre EPL & post EPL & pre EPL & post EPL \\
\hline Affected kidney to both total kidney uptake, $\%$ & $47.2 \pm 3.2$ & $48.1 \pm 4.1$ & $47.7 \pm 9.2$ & $43.3 \pm 10$ & $49.5 \pm 2.7$ & $52.8 \pm 3.2$ \\
\hline Affected calyx to ipsilateral kidney uptake, $\%$ & $21.6 \pm 1.3$ & $22.7 \pm 4.2$ & $24.1 \pm 6$ & $24.5 \pm 7$ & $22.2 \pm 1.9$ & $21.6 \pm 2.1$ \\
\hline
\end{tabular}

$\mathrm{p}$ values were between 0.13 and 0.18 (not statistically significant).

Ipsilateral kidney uptake is taken to be $100 \%$. The percent uptake shown in the second row is the percentage function of the affected calyx to the kidney function on the affected side.

was no significant change in the percentage function of the treated calyx to ipsilateral kidney function between the pre- and post-EPL scans $(\mathrm{p}<0.13)$. Also, the percentage function of the treated kidney to the total renal function did not significantly change after EPL $(\mathrm{p}<0.18)$.

\section{Discussion}

The use of EPL represents a major advance in the treatment of urinary calcular disease due to its effectiveness in disintegrating renal stones and the relative noninvasive nature compared to surgery. Many researchers are still investigating its short- and long-term effects on the kidney $[1,4,21]$ and as such many studies have been performed to evaluate the effect of EPL on renal function [4, 14, 22]. Gilbert et al. [9] evaluated several basic physiological parameters, including creatinine clearance, fractional sodium excretion, protein excretion, glomerular filtration rate, effective renal plasma flow and urinary osmolality before and after EPL to quantitate the changes in renal function. They found that the treated kidney

99mTc-DMSA Sectorial Scintigraphy before and after Lithotripsy for Calyceal Calculi appeared to maintain its ability to dilute urine and conserve sodium. They also reported that the renal physiological parameters correlated well with renal uptake of 99mTc-DMSA. Similar findings have been reported by Kaude et al. [22]. Groshar et al. [21] also found that EPL did not cause any effect on the renal cortical function of the treated kidney as determined by $99 \mathrm{~m}$ Tc-DMSA uptake.

99m Tc-DMSA renal scans have been shown to be ideal for evaluating long-term functional and morphological parenchymal sequelae of ESWL [16, 17, 23, 24]. Several studies have evaluated the renal parenchymal effects of ESWL using ${ }^{99 m}$ Tc-DMSA renal scan. Scarring has been observed in kidneys with calculi treated with ESWL about 3 months after treatment, the degree of scarring depending on the number of shock waves administered [18]. However, some of these lesions have been found to be reversible [19, 20, 25-27]. These studies have been essentially performed in children to assess any lasting damage to the immature kidneys [25-27]. In adults similar studies have also reported transient effects due to ESWL on the kidneys as determined by ${ }^{99 \mathrm{~m}}$ Tc-DMSA scans $[9,16,18$, 


\section{Anterior}

\section{Posterior}

RPO

LPO
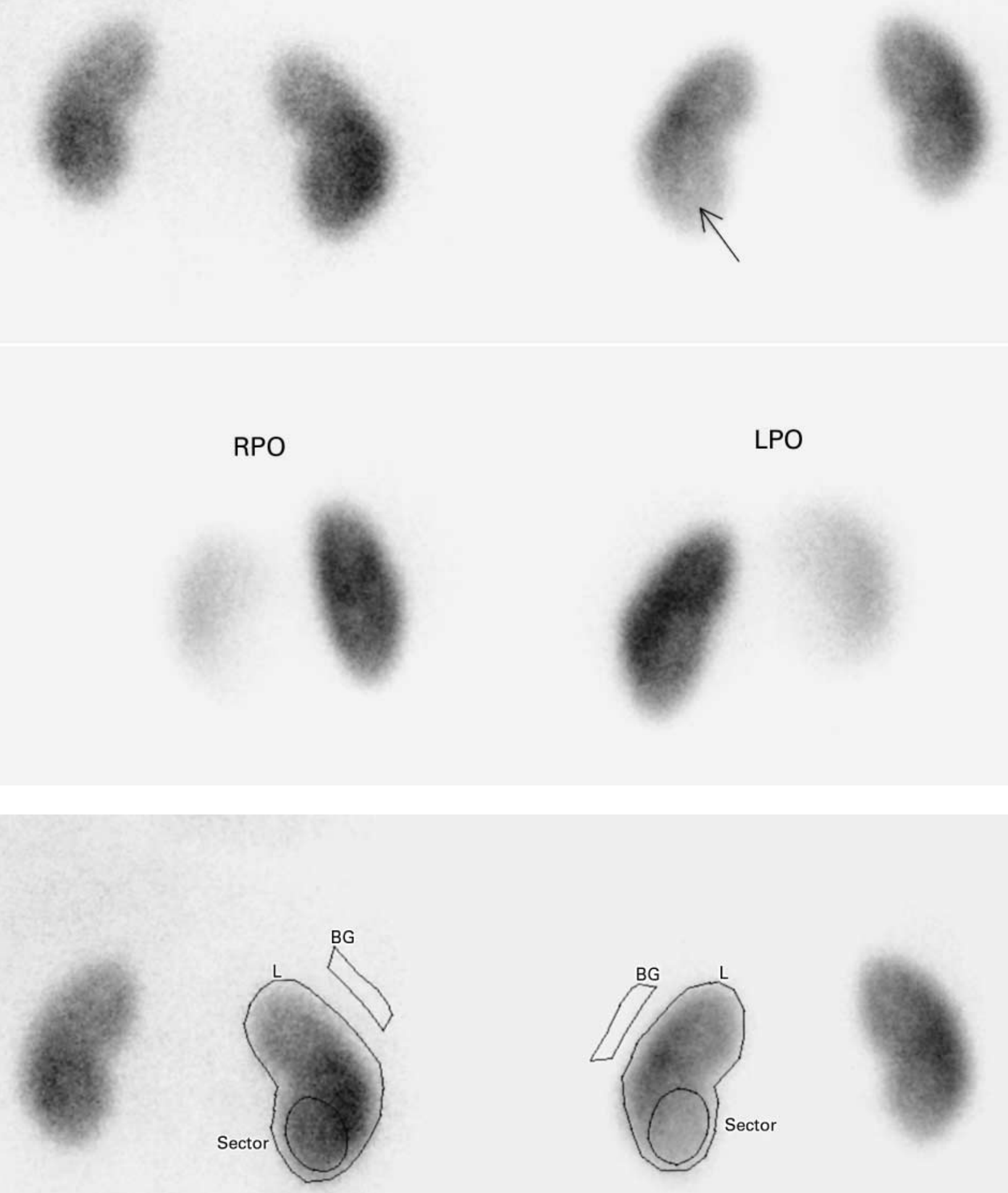

b 


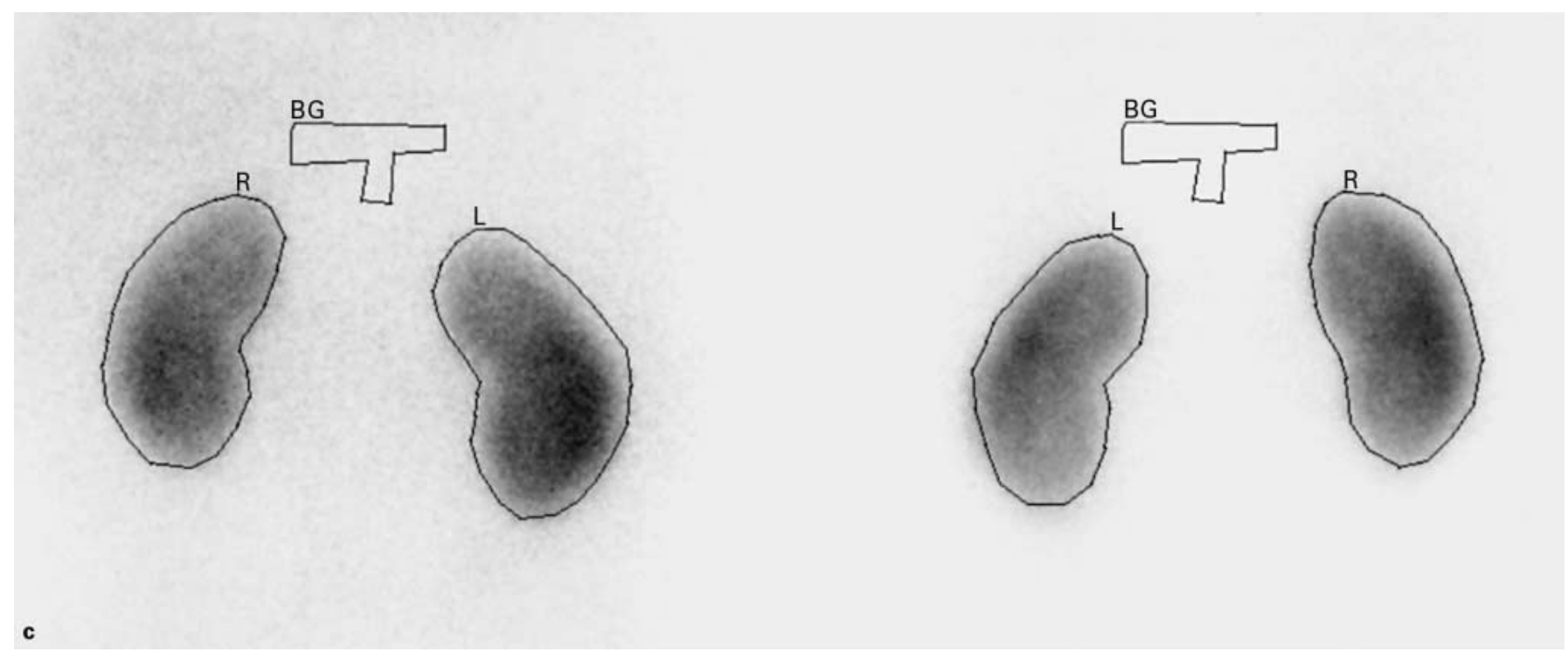

Fig. 1. a ${ }^{99 m}$ Tc-DMSA static images of the abdomen in multiple views in a patient with a lower calyceal stone of the left kidney. Decreased uptake is seen in the lower pole (arrow) corresponding to the location of the stone (pre-EPL scan). $\mathrm{LPO}=$ Left posterior oblique; RPO = right posterior oblique. $\mathbf{b}$ Sector analysis showing the region of interest around the lower calyx (Sector) and the whole kidney (L). BG = Background. c Split renal function analysis showing regions of interest around each kidney $(\mathrm{R}, \mathrm{L})$ and a background region $(\mathrm{BG})$.

20]. However, there have not been studies that have looked specifically at the function of the target area of the kidney as done in our study. A major disadvantage of studies assessing whole renal function using ${ }^{99 \mathrm{mTC}-D M S A}$ scintigraphy to see if any deleterious effect is produced by ESWL is the dilution effect of the focal abnormality by evaluating whole kidney uptake and the well-known phenomenon of compensation of function by the unaffected contralateral organ or the unaffected part of the same organ. Hence, subtle changes in function of a target part of the kidney may not be detected by whole renal ${ }^{99 \mathrm{~m} T c-}$ DMSA scan. In this study we have evaluated specifically the effect of EPL on the function of the target calyx as well as that of the whole of the affected kidney using ${ }^{99 \mathrm{~m} T \mathrm{~T}-}$ DMSA. The ipsilateral kidney was chosen for monitoring the effect on the sector function as a change in the ratio of the sector uptake to that in the whole kidney between baseline and post-EPL, thus providing a more reproducible way for assessing regional function. A slight underestimation of the damage from lithotripsy may have been introduced due to a slight decrease in the whole renal function on that side, leading to a smaller denominator in the calculated ratio. The percentage uptake of the sectorial and affected kidney showed no significant changes in the uptake values before and after treatment.
The overall stone clearance rate obtained in this study was $85 \%$ and is comparable to the result from most centres $[5,7]$. The stone clearance rates from the upper and middle calyces were $100 \%$. As with big renal calculi, the position of the calculi may influence the clearance rate. Thus even though calculi in the lower pole or calyx of the kidney may fragment, they may not necessarily be cleared due to the effect of the anatomical position of the calculi as well as the negative effect of gravity.

\section{Conclusion}

Using ${ }^{99 \mathrm{~m}} \mathrm{Tc}$-DMSA renal sector scintigraphy for monitoring the effect of EPL on the kidney, it was shown that EPL caused no significant damage to the function of either the target calyx or the whole kidney. Sector analysis provided a simple method for evaluation of regional renal function that would be more accurate for follow-up of localized injury to the kidney. 


\section{References}

1 Morris JS, Husman DA, Wilson WL, Preminger GM: Temporal effects of shockwave lithotripsy. J Urol 1991;145:881-883.

2 Tolley DA, Downey P: Current advances in shock wave lithotripsy. Curr Opin Urol 1999;9: 319-323.

3 Chaussy C: ESWL: Past, present and future. J Endourol 1988;2:97-100.

4 Chaussy C, Schmiedt E, Jocham D, Brendel W, Forsmann B, Walther V: First clinical experience with extracorporeal induced destruction of kidney stones by shock waves. J Urol 1982; 127:417-427.

5 Chow GK, Streem SB: Extracorporeal lithotripsy: Update on technology. Urol Clin North Am 2000;27:315-322.

6 Traxer O, Lottmann H, Archambaud F, Helal B, Mercier-Pageyral B: Extracorporeal lithotripsy in children: Study of its efficacy and evaluation of renal parenchymal damage by DMSA-Tc 99m scintigraphy: A series of 39 children (in French). Arch Pediatr 1999;6:251258.

7 Rodrigues Netto NR Jr, Longo JA, Ikonomidis JA, Rodrigues Netto MR: Extracorporeal shockwave lithotripsy in children. J Urol 2002; 167:2164-2166.

8 Morris JS, Husmann DA, Wilson WT, Denstedt J, Fulgham PF, Clayman RV, Preminger GM: A comparison of renal damage induced by varying modes of shock wave generation. J Urol 1991;145:864-867.

9 Gilbert BR, Riehle RA, Vaughan ED: Extracorporeal shock wave lithotripsy and its effect on renal function. J Urol 1988;139:482-485.

10 Williams CM, Kaude JV, Newman RC, Peterson JC, Thomas WC: Extracorporeal shock wave lithotripsy: Long-term complications. AJR Am J Roentgenol 1988;150:311-315.
11 Elsobky K, Sheir KZ, Madbouly K, Mokhtar AA: Extracorporeal shock wave lithotripsy in children: Experience using two second generation lithotripters. BJU Int 2000;86:851-856.

12 Lifshitz DA, Lingeman JE, Zafar FS, Hollensbe DW, Nyhuis AW, Evan AP: Alteration predicted growth rates of paediatric kidneys treated with shock waves. J Endourol 1998;12: 469-475.

13 Claro Jde A, Denardi F, Ferreira U, Rodrigues Netto N Jr, Saldanha LB, Figuerideo JF: Effects of extracorporeal shockwave lithotripsy, on renal growth and function in animal model. J Endourol 1994;8:191-194.

14 Conway JJ: The role of scintigraphy in urinary tract infection. Semin Nucl Med 1988;18:308319.

15 Loutfi I, Al-Zaabi K, Elgazzar AH: Tc-99m DMSA renal scan in first-time versus recurrent urinary tract infection: Yield and patterns of abnormalities. Clin Nucl Med 1999;24:931935.

16 Michaels EK, Pavel DG, Orellana P, Montes A, Olea E: Use of radionuclide renal imaging for clinical follow-up after extracorporeal shock wave lithotripsy of renal stones. J Urol 1992; 148:1015-1021.

17 Lottmann HB, Archambaud F, Hellal B, Pageyral BM, Cendron M: 99m technetium-dimercapto-succinic acid renal scan in the evaluation of potential long-term renal parenchymal damage associated with extracorporeal shock wave lithotripsy in children. J Urol 1998;159: 521-524.

18 Coulange C, Siles S, Rossi D, Vaillant JL, Soler B, Kaphan G, Rampal M: Quantitative renal DMSA scintigraphy after extracorporeal lithotripsy. Ann Urol (Paris) 1990;24:322-326.

19 Dumont M, Marchand L, Laroche B, Robert G, Thaber M: Scintigraphic evaluation of renal function after extracorporeal shock wave lithotripsy. Can Assoc Radiol J 1990;41:138-142.
20 Saussine C, Ansieau JP, Helwig JJ, Jacqmin D, Cuvelier D, Delepaul B, Bollack C: The scintigraphic effect of extracorporeal shock wave lithotripsy: A prospective series of 25 cases (in French). Prog Urol 1993;3:964-970.

21 Groshar D, Ginessin J, Moskovitz B, Frenke A, Israel O, Levin DR, Front D: Effect of extracorporeal piezoelectric lithotripsy shock waves on renal function mesured by Tc-99m-DMSA using SPECT. Urology 1991;38:537-539.

22 Kaude JV, William CM, Millner MR, Scott KN, Finlayson B: Renal morphology and function immediately after extracorporeal shock wave lithotripsy. AJR Am J Roentgenol 1985; 145:305-309.

23 Recker F, Hofmann W, Bex A, Tscholl R: Quantitative determination of urinary marker proteins: A model to determine intrarenal bioeffects after extracorporeal shock wave lithotripsy. J Urol 1992;148:1000-1006.

24 Rushton HG, Majd M: Dimercapto-succinic acid renoscintigraphy for the evaluation of pyelonephritis and scarring: A review of experimental clinical studies. J Urol 1992;148:17261732.

25 Goel MC, Baserge NS, Babu RV, Sinha S, Kapoor R: Paediatric kidney: Functional outcome after extracorporeal shock wave lithotripsy. J Urol 1996;155:2044-2046.

26 Kaji DM, Xie HW, Handy BE, Sherrod A, Huffman JL: The effects of extracorporeal shock wave lithotripsy on renal growth, function and arterial blood pressure in an animal model. J Urol 1991;146:544-547.

27 Marberger M, Turk C, Steinkogler I: Piezoelectric extracorporeal shock wave lithotripsy in children. J Urol 1989;142:349-352. 